\section{Locomotor delayed alternation by prefrontally ablated monkeys*}

\author{
J. S. STAMM, IRENA STEPIEN, and M. LEVINE \\ State University of New York, Stony Brook, N.Y. 11790
}

Two monkeys whose dorsolateral prefrontal cortex had been ablated were tested on delayed alternation tasks in a locomotor maze. They responded correctly after they had developed pronounced positional habits in the startbox, but disruption of such habits resulted in impaired performance. The addition of visual cues led to new positional habits and improved performance. The results are interpreted in terms of the kinesthetic functions of prefrontal cortex.

The findings from a previous investigation (Stamm, 1970) indicated that bilateral ablation of dorsolateral prefrontal cortex in monkeys results in severe and long-lasting impairments of delayed alternation (DA) performance, both in the standard Wisconsin General Test Apparatus (WGTA) and in a locomotor maze. Although the majority of monkeys responded only at near-chance level after extensive postoperative training, correct performance was reattained relatively rapidly by 1 of 4 monkeys tested in the WGTA and by 2 of 10 monkeys in the maze. It was observed that the two maze monkeys developed the habit of quietly sitting in the starting compartment during the intertrial delay and holding one hand to the door from the return alley through which they had just passed (Fig. 1). The significance of this self-imposed positional habit on DA performance is further evaluated in the present experiment.

SUBJECTS AND APPARATUS

The Ss were two of the prefrontal monkeys that had been trained in the previous experiment (Stamm, 1970). They were tested in a locomotor maze (Fig. 1) which consisted of a series of compartments separated by sliding panels or swinging doors. For the standard DA task (DAs), the monkey was confined in the startbox. When $E$ raised the opaque screen, the monkey could traverse the approach alley and pass through either the left or the right choice doors (the transparent screen remained open). When the monkey opened either of these doors, the other door was locked automatically. Food cups were mounted on the walls of the two return alleys. The swinging doors leading to the startbox also locked automatically after the monkey had entered it. The choice doors contained plastic windows, $10 \times 10 \mathrm{~cm}$, which could be illuminated from the rear.

*This experiment was conducted at Queens College, City University of New York, with the support of USPHS Grants MH-08064 and MH-14300.
The monkeys were trained on DAs at 30 rewarded trials per session. On the first trial of each session (unscored) both food cups contained a peanut reward and on subsequent trials the reward was given in the food cup that was not chosen on the previous trial. The correction procedure was followed, so that after a wrong response the reward remained in the same food cup until the monkey made a correction response. Unrewarded responses after the first wrong response (initial error) of a trial were not counted as trials, but were scored separately as repetitive errors. The 15-sec delay was timed between the monkey's opening of the choice doors and raising the opaque panel by $E$. Both windows in the choice doors received white illumination. During postoperative training on the DAs task, S 83 had responded only at $54 \%$ correct after 920 trials, whereas S 33 attained $90 \%$ correct performance after 310 trials. This monkey had developed the position habit during the intertrial delay, as illustrated by Fig. 1 .

\section{PROCEDURE AND RESULTS} Variations in Delay

S 33 was tested on delays of 15,30 , and $45 \mathrm{sec}$ for a total of 150 trials. His correct responses were $85 \%, 75 \%$, and $40 \%$, respectively, with each of these delays. It was observed that for those trials, regardless of the delay, when the monkey held his hand on the door throughout the delay, his responses were $92 \%$ correct, whereas if he withdrew his hand, he made perseverative responses to one side. S 83 was tested without any imposed delay. With all maze doors open, he rapidly walked through the maze at an average of less than $10 \mathrm{sec}$ per trial and responded at $94 \%$ correct. However, when he was stopped briefly (about $1 / 2 \mathrm{sec}$ ) by the closed starting door, he responded at $46 \%$ correct. Disnuption of Positional Habits

The task was modified by keeping the opaque screen from the startbox open and delaying the monkey with the transparent screen in front of the choice doors (Fig. 1). Whereas $S 33$ responded during retraining on DAs at $93 \%$ correct, his responses during 410 trials with the modified procedure never rose above $60 \%$ correct and were at chance level during the final 90 trials.

\section{Addition of Visual Cues}

Differential illumination was provided to the windows in the choice doors, with the left door receiving $7 / \mathrm{sec}$ flickering blue light and the right door continuous blue light of the same intensity. Each monkey was trained on that 15-sec DA task on which he had failed. As indicated by Table 1, the correct response rates for both monkeys remained near chance level during the first 20 sessions with equal illumination, but then rose significantly during the 20 sessions with differential illumination. During the course of flicker training, both monkeys appeared to develop positional cues, as indicated by the following observations: for S 33-"Monkey goes from either return alley through the startbox to the closed transparent door, then returns to the start box and sits on the side from which it had just come until the transparent screen is raised." This behavior was first observed during flicker training and continued during equal-illumination testing. For S 83-"No obvious positional habits were observed. During flicker training the monkey started to orient his responses toward the click of the solenoid that was mounted on the return alley doors. He then responded to the side opposite from which he had heard

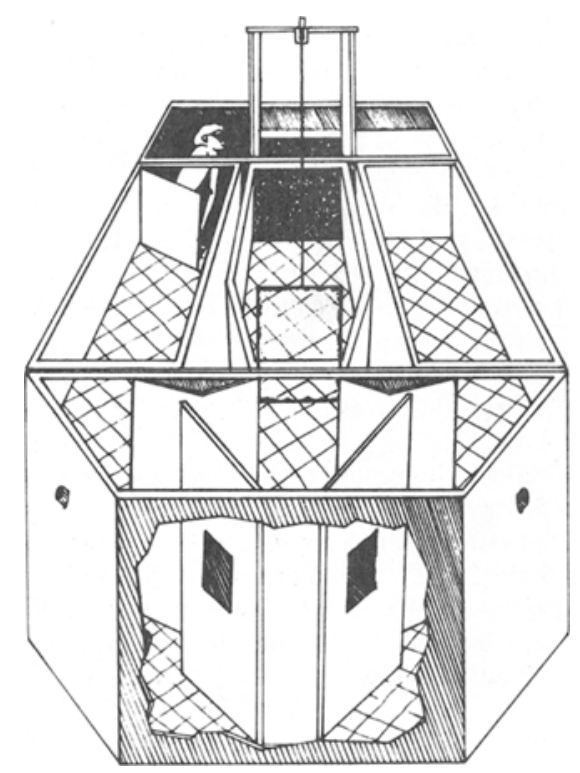

Fig. 1. Sketch of monkey in locomotor maze, waiting during delay in startbox for opening of opaque screen. Note the transparent screen near the choice doors which is in open (raised) position. 
Table 1

Delayed Alternation with Equal or Differential Illumination of the Choice Doors

\begin{tabular}{|c|c|c|c|c|c|}
\hline \multirow[b]{2}{*}{ Illumination } & \multirow[b]{2}{*}{ Sessions } & \multicolumn{2}{|c|}{ Percent Correct } & \multicolumn{2}{|c|}{ Rep. E:T*** } \\
\hline & & 533 & $\mathrm{~S} 83$ & $\$ 33$ & $\mathrm{~S} 83$ \\
\hline $\begin{array}{l}\text { Equal* } \\
\text { Equal }\end{array}$ & $\begin{array}{c}1-3 \\
18-20\end{array}$ & $\begin{array}{l}49 \\
56\end{array}$ & $\begin{array}{l}35 \\
44\end{array}$ & $\begin{array}{l}0.66 \\
0.15\end{array}$ & $\begin{array}{l}6.15 \\
0.49\end{array}$ \\
\hline $\begin{array}{l}\text { Differential** } \\
\text { Differential }\end{array}$ & $\begin{array}{c}1-3 \\
18-20\end{array}$ & $\begin{array}{l}50 \\
68\end{array}$ & $\begin{array}{l}59 \\
76\end{array}$ & $\begin{array}{l}0.17 \\
0.09\end{array}$ & 0.12 \\
\hline $\begin{array}{l}\text { Equal } \\
\text { Differential } \\
\text { Equal }\end{array}$ & $\begin{array}{l}1-3 \\
1-3 \\
1-3\end{array}$ & $\begin{array}{l}64 \\
72 \\
72 \\
\end{array}$ & $\begin{array}{l}71 \\
71 \\
78\end{array}$ & $\begin{array}{l}0.07 \\
0.10 \\
0.09\end{array}$ & $\begin{array}{l}0.04 \\
0.02 \\
0.06\end{array}$ \\
\hline
\end{tabular}

* Both choice doors illuminated by continuous lights.

* *Illumination of right door by continuous, left door by 7 -sec flickering light

${ }^{* * *}$ Repetitive errors per trial. monkeys such cues are so subtle that they cannot be readily observed, whereas the present monkeys developed exaggerated positional habits that seemed to compensate for their prefrontal impairments.

\section{REFERENCES}

KONORSKI, J. Integrative activity of the brain. Chicago: University of Chicago Press. 1967. LURIA, A. R. Human brain and psychological processes. New York: Harper \& Row, 1966.

STAMM. J. S. Dorsolateral frontal ablations and response processes in monkeys. Joumal of Comparative \& Physiological Psychology, $1970,70,437-447$ the click. During several test trials, when the solenoid was inoperative, the monkey made more errors."

\section{DISCUSSION}

The development of strong positional habits by prefrontally ablated animals has also been reported by Konorski (1967), who observed that some dogs responded correctly on a locomotor delayed-response task by maintaining their body orientation toward the baited feeder during the delay period. Since the dogs then walked directly to the feeder, Konorski considered their behavior as a "pseudodelayed" response. In the present experiment, however, the monkeys were required to follow a complex sequence of motor responses involving several locomotor turns. The finding that prefrontal monkeys could walk through the maze with correct alternations, but failed on the task when their movements were briefly interrupted, suggests that prefrontal cortex is not essential to the execution of sequential motor acts per se. Konorski's formulation of prefrontal cortex as the locus for "kinesthetic gnosis" does not specify whether these neuronal structures function in the establishment of the relevant kinesthetic cues or in the execution of motor acts in accordance with such cues. The present findings point to the second interpretation as the more plausible. The interpretation is consonant with Luria's (1966) formulation of prefrontal cortex functioning as a guidance system for the execution of complex motor acts, in accordance with previous instructions. Whereas such guidance is mediated verbally by human Ss, it is dependent upon kinesthetic cues in the monkey In normal

\title{
Stimulus compounding and response summation with an instrumental running response
}

\author{
LAURENCE MILLER and RONALD D. PRICE \\ Western Washington State College, Bellingham, Wash. 98225
}

A light and a tone each maintained a certain speed of an instrumental running response in a straight alley. When the light and tone were combined, their compound maintained a faster running speed than that maintained by either the light or tone alone. The results were interpreted in terms of summation of the response tendencies maintained by each stimulus and further demonstrated the wide generality of this phenomenon.

When two conditioned (CS) or discriminative $\left(\mathrm{S}^{\mathrm{D}}\right)$ stimuli, each capable of maintaining a response, are combined, their compound may produce a response which is stronger than the response maintained by either stimulus alone. This effect has been described as summation of the response tendencies maintained by each stimulus. Summation of responding has been demonstrated to have generality over several conditioning paradigms and several measures of response strength: (1) Classical conditioning-a compound $\mathrm{CS}$ has been shown to elicit a greater magnitude of salivation (Pavlov, 1927) or galvanic skin response (Hull, 1940; Grings \& O’Donnell, 1956) than the magnitude elicited by either CS alone. (2) Free-operant conditioning-Wolf (1963), Weiss (1964), and Miller \& Ackley (1970) demonstrated that a compound $S^{D}$ maintained a higher rate of response than the rate maintained by each SD alone. (3) Conditioned suppression-Miller (1969a), Reberg \& Black (1969), Van Houten, O'Leary, \& Weiss (1970), and Cappell, Herring, \& Webster (1970) found that when individual CSs, which each suppressed rate of leverpressing, were combined, this compound suppressed responding even more. (4) Discriminated instrumental avoidance-Miller (1969b) demonstrated that when a light and buzzer, which separately maintained a latency of avoidance response in a two-way shuttlebox, were combined, the latency to this compound was shorter than the latency to either single stimulus.

The present study attempted to extend further the generality of compounding summation to a third measure of instrumental response strength, speed of running. Summation of response tendencies would predict that if two stimuli, which each maintained a certain speed of running, were combined, the speed maintained by the compound would be greater than the speed maintained by either single stimulus.

\section{PROCEDURE}

The Ss were four male albino rats about 150 days old. They were maintained at $80 \%$ of free-feeding weight for the course of the experiment. The apparatus was a $75 \times 7 \times 8$ in. straight alley painted flat black and covered with screen. The runway 